The study of attitude and motivation towards learning English as foreign language to public and private secondary and higher secondary school students in Pakistan: A comparative study

Bajwa, Imran $\triangle$

Iqra University, Karachi, Pakistan (linguisticscholar@gmail.com)

Younas, Muhammad

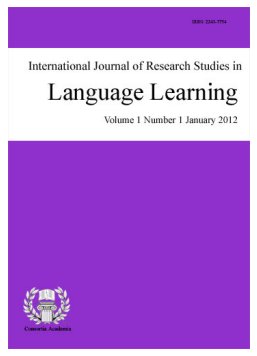

ISSN: 2243-7754 Online ISSN: 2243-7762

OPEN ACCESS

Iqra University, Karachi, Pakistan (Younis.farid@gmail.com) $\begin{array}{ll}\text { Received: 22 July } 2018 & \text { Revised: } 7 \text { December } 2018 \\ \text { Available Online: } 14 \text { February } 2019 & \text { DOI: } 10.5861 / \text { ijrsll.2019.3007 }\end{array}$

Accepted: 15 January 2019

\title{
Abstract
}

The present comparative exploratory study aimed to discover and compare the attitudes and motivational orientation of secondary and higher secondary public and private school students in Pakistan in learning English as foreign language. The study was based on the socio-educational model proposed by Gardner (2010) exploiting the psychological aspects like attitude and motivation of human cognition in learning English as a second or foreign language. The stratified random sampling technique was used to select 400 participants for the study, 200 each from public and private sector. Data collection tool was adopted from Gardner's attitude and motivation test battery (AMTB) with 38 items on a six point Likert scale. Collected data from the survey was statistically analyzed using SPSS 22 to check the favorable patterns. Exploratory factor analysis (EFA) was used to check the co-linearity among the variable items and the reliability of the scale was ensured through the reliability statistics (reported Alpha .903). Independent-sample t-test was performed to compare the mean values of motivation and attitude of the public and private sector students. In addition to that, a similar comparison was made on the basis of students' gender. The result of the t-test indicated that the private sector students possessed higher level of attitude and motivation in learning English as foreign language as compared to the public sector students. Similarly, the motivational orientation and attitude towards learning English of female students were higher than that of male students. Furthermore, the overall level of motivation and attitude of the students in both sectors found high. The study bears implications for different stakeholders with a lead for future researchers in the same field.

Keywords: attitude; motivation; public; private; secondary schools; Pakistan 


\section{The study of attitude and motivation towards learning English as foreign language to public and private secondary and higher secondary school students in Pakistan: A comparative study}

\section{Introduction}

Language learning, according to linguistics scholars, is a foundation stone of human subsistence on earth. The knowledge of a language helps us to express our thoughts, emotions, ideas, and opinions in a society (Akram, 2015). In foreign language learning context, there are various factors which influence the language learning process such as anxiety, learning achievements, aptitude, age, and personalities (Grey, Williams, \& Rebuschat, 2015). Similarly, the learner, the teacher and the instructional materials are the most recognizable ingredients in the teaching of a second/foreign language. However, there are other important factors which normally operate less overtly and sometimes invisibly in the background. These include educational policies, course administration, teaching methodologies, the objectives of learners, external language exposure, and the availability of learning centers and libraries (Al-Mahrooqi, Hassan, \& Cofie, 2012; Issan \& Gomaa, 2010). All these factors are either tangible or measurable and can be decreed into action, engineered by management planning, or implemented with budgets. There is, however, one missing ingredient which researchers and practitioners consider so important that all the other factors might be ineffective without it. This ingredient is motivation - the force which drives learners to make optimal use of the available learning resources and achieve their learning objectives (Manzoor, Ahmed, \& Gill, 2014).

Motivation plays an important role in generating the initial ignition which produces learning and later molds that learning into a continuous process of knowledge acquisition that ends up in a final product in the shape of foreign language acquisition (Cheng \& Dornyei, 2007). As motivation is a psychological aspect of human cognition, it provides the learner an instrumental force in the other elements of language acquisition process and ultimately produces the required favorable results in the form of successfully learning a second language. In addition to the above, Dornyei and Otto (1998) define motivation as a dynamic and continuously varying cumulative stimulus in a person that coordinates, initiates, amplifies, directs, terminates, and evaluates the cognition and motor processes in which preliminary desires and wishes are selected, organized, operationalized, prioritized, and acted out in human mind successfully or unsuccessfully. The comprehensive definition of motivation proposed by Dornyei and Otto reveals almost all significant aspects of the construct relevant to the present study.

Consequently, motivation in the present study is a dynamic stimulus within an individual which activates mental and physical activity, creates desires and realizes them with or without success. The significant role played by motivation in second language learning among young and adult learners have been recognized by the language scholars as earlier as in the mid of $20^{\text {th }}$ century. In this context, Dornyei (2001) identified that an aptitude for language acquisition is not the only aspect responsible for successfully learning the second or foreign language. For them, the second language (henceforth L2) achievement of the learner is enhanced through the ability of the learner to implement a range of behavioral patterns which are the symbols of the target language culture-the language spoken by the people of the target area. In this regard, teachers of the target language can play a vital role in accelerating the motivation level of the students in certain situations where the motivation opportunities have been or on the verge of submergence in the environment of the target language (Rehman \& Haider, 2013). Hence, the motivation level of the target language learners might be improved through the teachers of that language.

In addition to motivation as an effective factor responsible for second language learning, various other aspects of human psychology are also explored in the wake of $2^{\text {nd }}$ language acquisition. The explored literature 
supports the significance of learners' attitudes towards learning English language in different language learning environmental contexts. Although, most of the studies on learners' attitudes propound certain similarities, but the differences also exist that need to be explored continuously. The subsequent section of the study is designed to highlight the importance of various attitudes towards learning second language along with its embedded factors.

\section{Literature Review}

In the domain of social psychology, learners' attitude is broadly defined as the 'summary evaluation' of the target language that might possess suitable or comparatively less suitable inclinations (Eagly \& Chaiken, 2007). As the attitude requires cognitive, behavioral, and affective responses from the learners along with the sum of influence it exerts upon their perceived information processing, it is important to explore the impact of attitude on language learning in the domain of education psychology (Busse, 2017). Additionally, Gardner's (1985) study particularly focusing on second language learning has long proved that an individual's attitude towards second language acquisition are related to the identity factor and are usually transformed by the parental or family background, group membership, and societal views. Along with the constructs mentioned previously, multiple socio-cultural and contextual variables in the initial phase of schooling, including the teachers' attitudes, classroom interaction, peer group, and the educational institution itself shape and engender the attitudes of the learners (Kormos, Kiddle, \& Csizer, 2011).

English as foreign language teachers often exercise the conventional and traditionally acknowledged motivational strategies in classrooms, while practically no limit has been assigned for the range of possible motivational strategies to be used. The EFL teacher can adopt a range of different motivational strategies depending upon the classroom circumstances and the socio-cultural background of the students, in particular the strategies which are formulated for language instruction in formal classroom settings. The strategies which are available for the teachers to choose from are usually derived from the personal experiences of teachers or from the findings of scholarly research studies. In this context, Kolb and Kolb (2005) favors the use of motivational strategies on the basis of taking into consideration the individual learning styles of the students while Barnett, Pearson, Pearson, and Kellermanns (2014) advocates the use of technology in teaching the students and thus enhancing their motivation level in all subjects with special focus on language learning. Similarly, Liu and Lin (2017) recommend the use of popular culture in the classroom while Bekiari and Petanidis (2016) support the idea of teachers' proximity in the interpersonal behavior towards their students. However, it is pertinent to mention here that the range is so wide in terms of selection and effectiveness of motivational strategies that practically it is implausible to think about only one strategy at a time as multiple motivational strategies work in different situations and learning contexts (Dornyei, 2001). Motivation is considered as a critical factor in the process of $2^{\text {nd }}$ language acquisition (Shakfa \& Kabilan, 2017). In this regard, Noreen, Ahmed, and Esmail (2015) believe that the success or failure of the students depend on their motivation level and the less motivated students usually fail in accomplishing their goals as compare to the students with higher level of motivation.

Effective motivation and positive attitudes towards second or foreign language acquisition have been linked with a strong thrust for proficiency in the target language (Dornyei, 2001). While teaching English as foreign language in Pakistani context, the EFL teachers face unique challenges while teaching English with regard to the attitude and motivation level of the students (Ali \& Pathan, 2017). Another possible reason for the perceived failure to achieve adequate level of English language proficiency and learning $2^{\text {nd }}$ language effectively is due to higher degree of de-motivation among the students (Nawaz, Amin, \& Tatla, 2015). In this regard, Gardner (2007) states that the increased dampening in the motivation level of some EFL learners is due to the high degree of incompatibility between the L1 language and culture and that of the language and culture of English (Gardner, 2007).

The current study on attitude and motivation is based on Gardner's socio-educational model. Gardner (2010) started to formulate his socio-educational model with regard to the role of motivation in $2^{\text {nd }}$ language learning as early as in 1960s, and continuously modified it until now (Lovato \& Junior, 2011). In this context, Gardner also 
proposed the hypothesis that second language learners showing positive attitudes toward the people and culture of the target language will learn that target language more easily and effectively as compared to those who do not build healthy attitudes (Gardner, 2006). Hence, the learners who possess a strong desire and passion with good motivation towards learning English as foreign language can achieve their goal of language learning quite easily. Furthermore, Gardener (2010) proposed that motivation plays a threefold role in the social-educational model with its components namely: desire, enjoyment, and effort. Firstly, the motivated students must put forth their paramount efforts by using each of their free moment in learning English language. Secondly, the students should possess the required passion in order to express their strong will and wish to acquire the knowledge of English language. Lastly, the students may pose feelings of enjoyment during the language learning process. In addition to that, he postulated that there are two types of motivation namely: instrumental and integrative motivation.

\subsection{Aims and objectives of the study}

When all the concrete or physical constructs which could prove productive in students' second language acquisition have been exhausted, then it becomes logical to move towards the psychological constructs, for example, attitude and motivation. As it is the psychological aspect of human nature, the most appropriate tendency would be to it entirely in context of students' own interest or efforts. However, in the current research, the sole motive of the researcher is confined to check the function of attitude and motivation in relation to learning English as a foreign language in formal classroom settings and the ability of these constructs to inspire the students to accomplish their language learning goals by taking into account the social class and cultural differences among various students. The main purpose, therefore, is to carry out, in Pakistan, a modified version of the study already conducted by Khalid (2016) on English as foreign language students, keeping in view the difference in teaching approaches and classroom environment of public and private schools by comparing the attitudes and motivational level of the two entities.

Consequently, the foremost objective of the study is to identify the attitudes of the Pakistani students towards English and the significant effect of these attitudes towards the motivational level of the students to learn and communicate in English so as to achieve better level of education imparted to these students as the educational policy in Pakistan focuses towards gradual use of English as the language of instruction at elementary, secondary, and higher secondary level. Furthermore, as there are both public and private school systems in Pakistan with private schools focusing more towards English (Rahman, 2010), so the need arises to discover the attitude and motivational orientation of the private school students towards English language as well.

In consequence to the above situated reasons, this research paper tries to examine what the teenaged high school students believe towards and motivate for English as the language of academic activities and day-to-day communication. In addition to that, a comparison of attitude and motivational preview of the public and private high school students has also been made through this research paper so that it could help the management, policy makers, and other stakeholders to better understand the viewpoint of the students in order to develop better policy guidelines which could help impart better quality of education in Pakistan for its progress and prosperity.

Thus, the objectives of the current research are discussed as:

$>\quad$ To explore the attitudes of Pakistani secondary school students towards learning English as foreign language

$>\quad$ To examine the motivational approach of secondary level students in Pakistan towards English as language of communication and academic activities

$>\quad$ To identify by comparing the differences of attitude and motivational level of the public and private secondary school students in learning English as foreign language Pakistan 
Attitude and motivation towards English as foreign language to secondary school students in Pakistan

$>$ To determine the difference of motivation among the students on the basis of their gender

In order to fulfill the above mentioned research objectives, following research questions are developed:

$>\quad$ What are the attitudes of Pakistani secondary school students towards learning English as a foreign language?

$>\quad$ What are the motivational orientations of Pakistani secondary level students towards learning English as language of communication?

$>\quad$ To what extent do attitude and motivational level of public and private secondary school students differ in learning English as foreign language in Pakistan?

$>$ How do the motivation and attitude of the students differ on the basis of their gender?

\subsection{Rationale for the study}

There are high social class differences in Pakistani education system with ordinary schools and colleges follow the examination system of the recognized Boards and elite schooling in urbanized cities usually follow the western education system, for example, O/A levels. The establishment of private schooling system within the jurisdiction of government Boards and higher education commission (HEC) is another developing phenomenon within Pakistan. Private schools and colleges impart quality education with improved facilities and trained faculties. Due to the better literary and pedagogic environment in private setup, most of the students are taking admissions in private schooling system (Mahboob, 2017). Due to its importance in Pakistani education system, it is highly essential that such a study must be carried out which might compare the attitude and motivation level of the public and private school systems, particularly at secondary and higher secondary level in order to get a deep insight to the motivational orientation among the students of both private and public schools and colleges. As most of the studies related to L2 motivation and attitude has mostly been carried out taking respondents from university students (Boo, Dornyei, \& Ryan, 2015), so it is highly indispensable point to study the attitudes of younger and teenaged students of secondary and higher secondary level.

Moreover, the study of differences in $2^{\text {nd }}$ language learning motivation between students at different levels of education is imperative that can contribute to more precise and customized pedagogical implications in the domain of teaching and learning of $2^{\text {nd }}$ language. In the consequences stated above, it is highly important that such a study should be carried out which might figure out the attitude and motivation level of the public and private students in learning English as a source of communication particularly at their teenage. To fulfill such a need, the present study has been conducted to lay foundation for such a comparative analysis which has not yet been done at any level in Pakistan.

\section{Research Methodology}

The current research is entirely based on the use of quantitative methods of data collection and data analysis. An adequate sampling size, however, was taken in order to validate the significance of the single research technique used for the study. In addition, stratified random sampling technique was used to administer the research tool on 400 respondents from a range of population, which is discussed below in ample details.

\subsection{Population and Sampling}

As the current study was comparative in nature (to compare the attitude and motivational orientation of secondary and higher secondary public and private school/college students), so all male and female students of secondary and higher secondary schools as well as intermediate colleges at public and private sector in district Bahawalpur. The rationale to choose district Bahawalpur in particular for the study lies in the fact that mostly the big cities in Pakistan particularly Karachi, Hyderabad, Lahore, and Islamabad contain heterogeneous population 
Bajwa, I., \& Younas, M.

with diverse ethnic and pedagogic backgrounds. So, it seems difficult to locate homogenous population with identical linguistic and literary skills in order to justify the comparison made on the basis of attitude and motivation towards learning English as a foreign language.

Table 1

Sampling statistics

\begin{tabular}{lcc|lcc}
\hline \multicolumn{1}{c}{ Gender } & $n$ & $\%$ & Edu Mode & $n$ & $\%$ \\
\hline Male & 230 & $57.5 \%$ & Public & 200 & $50 \%$ \\
Female & 170 & $42.5 \%$ & Private & 200 & $50 \%$ \\
$\quad$ Total & 400 & $100 \%$ & Total & 400 & $100 \%$ \\
\hline
\end{tabular}

Table 2

Sampling statistics

\begin{tabular}{|c|c|c|c|c|c|}
\hline Age & $n$ & $\%$ & M/Tongue & $n$ & $\%$ \\
\hline 16 years & 70 & $17.5 \%$ & Urdu & 126 & $31.5 \%$ \\
\hline 17 years & 158 & $39.5 \%$ & Punjabi & 243 & $60.8 \%$ \\
\hline 18 years & 125 & $31.3 \%$ & Saraiki & 30 & $7.5 \%$ \\
\hline 19 years & 47 & $11.8 \%$ & Pushto & 1 & $0.3 \%$ \\
\hline Total & 400 & $100 \%$ & Total & 400 & $100 \%$ \\
\hline
\end{tabular}

Stratified random sampling technique (Acharya, Prakash, Saxena, \& Nigam, 2013) was used to collect 400 samples of the students between the age group ranging from 16 to 19 years who were studying different programs in five different colleges of Bahawalpur. The population was divided into two strata namely public and private and then random sampling was used to sort out 200 participants from each stratum. There were 14 students who were more than 20 years old who were replaced with their colleagues from the same colleges, as the main focus of the study was to gain the view point of the teenaged students. The parity was maintained while collecting data regarding the number of students involved in the study. Therefore, 200 students from three private colleges and 200 students from two government colleges were selected to participate in the study. The availability of both male and female participants was ensured through the selection of sampling from both male and female colleges. Furthermore, there was a significant contribution from students on the basis of mother tongue. There were students having three main mother tongues including Urdu, Punjabi, and Saraiki, while one student belonged to Pushto speaking family.

\subsection{Data collection instrument}

The tool for data collection was adopted from Gardner's (1985) study of Attitude and Motivation Test Battery (AMTB). The AMTB is a quantitative survey containing 104 items divided into different variables on a six point Likert scale ranging from 1 to 6 , where 1 represents strongly disagree while 6 shows the strongly agreed point without having a neutral value. The researcher however picked 38 items from different variables like motivation intensity, desire to learn English, attitude towards learning English, and instrumental as well as integrative motivational orientation along with 15 items in the instrument coded negatively in order to provide a well-shaped view of the participants' attitude and motivational orientation towards English as a foreign language in Pakistan. The said items were modified into Pakistani context through using synonyms and suitable replacement phrases for the difficult words/phrases used in the questionnaire in order to let it understand by the young students of secondary school level. The researcher himself administered the survey questionnaire by physically visiting all five colleges instead of seeking research assistant. Furthermore, the reliability of the instrument was ensured through running the reliability analysis feature of the statistical package for social sciences (henceforth SPSS) version 22 software and a combined Alpha of all items was reported as 0.903, which is a suitable evidence for the reliability of the instrument items. In addition to this, the first part of the questionnaire contains demographic information like gender, age, mother tongue, and mode of education (public/private) from the students which is essential for the analysis of the current study. 


\section{Data Analysis and Discussion}

This part of the research deals with the different tools and tests injected into the collected data through using SPSS in order to scrutinize and analyze the data for better understanding of the respondents' point of view and hence making a better predictions and future recommendations for the concerned stakeholders regarding students' motivation and attitude towards learning English. The subsequent headings deal with the statistical representation of data.

\subsection{Reliability Analysis}

The researcher has categorically ensured the reliability of the instrument and collected used for the study by running reliability analysis test through SPSS. The consistency of the multiple items scale is ensured through reliability analysis. The value of the reported Alpha is normally used to check the consistency and reliability when multiple items of a scale are used as a sum to exert a combine effect on the individual items of the scale (Raza, Jawaid, \& Hassan, 2015). The computation method of Alpha is normally based on the mean value of correlation with every other item in the scale. The value of Alpha should be greater than .5 to be considered as the appropriate correlation among the scale items. The reported Alpha value in this case was .90 which indicates a high reliability factor among the scale items. The combined as well as individual variable reliability is given in the table below.

\section{Table 3}

Reliability statistics

\begin{tabular}{lcc}
\hline \multicolumn{1}{c}{ Variable Name } & No of Items & Alpha Value \\
\hline Overall & 31 & .90 \\
Motivation Intensity & 05 & .60 \\
Desire to Learn English & 02 & .51 \\
Attitude towards English & 05 & .77 \\
Inst/Integrative Motivation & 06 & .77 \\
Motivational Orientation & 13 & .88 \\
\hline Source: Author's own estimation & &
\end{tabular}

\subsection{Sampling Adequacy}

An adequate sample size for data collection is considered as the backbone of a good research. The researcher used Kaiser-Meyer-Olkin (henceforth KMO) and Bartlett's test to verify the adequacy of the sampling size for the current research. As a rule of thumb, the KMO value must be greater than .50 to recognize the appropriate sample size for the variables in scale items. Resultantly, the KMO value for the current research was found to be .89 , indicating that an adequate sample size was obtained for the current research. The details of the KMO and Bartlett's test for sampling adequacy have been given in the table below.

\section{Table 4}

KMO and Bartlett's Test

\begin{tabular}{lll}
\hline Kaiser-Meyer-Olkin Measure of Sampling Adequacy. & .89 \\
Bartlett's Test of Sphericity & Approx. Chi-Square & 4163.97 \\
& Df & 465 \\
& Sig. & .000 \\
\hline
\end{tabular}

\subsection{Factor Analysis}

The statistical device known as factor analysis is a significant measure through SPSS which determines the level of co-linearity among items of a variable. It is also used for data reduction, as the process involves the use of factor items which perfectly fits in the variable group, thus, sometimes it is required to eliminate certain items to get a suitable grouping in a said variable. 
Bajwa, I., \& Younas, M.

\section{Table 5}

Principal components analysis

\begin{tabular}{|c|c|c|c|c|c|}
\hline Items & MI & DLE & ALE & MO & MOT \\
\hline A1 & .556 & & & & \\
\hline A2 & .652 & & & & \\
\hline A3 & .538 & & & & \\
\hline A4 & .498 & & & & \\
\hline A5 & .466 & & & & \\
\hline B1 & & .714 & & & \\
\hline B2 & & .668 & & & \\
\hline $\mathrm{C} 1$ & & & .643 & & \\
\hline $\mathrm{C} 2$ & & & .702 & & \\
\hline C3 & & & .512 & & \\
\hline C4 & & & .575 & & \\
\hline C5 & & & .462 & & \\
\hline D1 & & & & .704 & \\
\hline D2 & & & & .727 & \\
\hline D3 & & & & .360 & \\
\hline D4 & & & & .739 & \\
\hline D5 & & & & .486 & \\
\hline D6 & & & & .531 & \\
\hline E1 & & & & & .522 \\
\hline E2 & & & & & .582 \\
\hline E3 & & & & & .605 \\
\hline E4 & & & & & .641 \\
\hline E5 & & & & & .635 \\
\hline E6 & & & & & .660 \\
\hline E7 & & & & & .681 \\
\hline E8 & & & & & .668 \\
\hline E9 & & & & & .596 \\
\hline E10 & & & & & .464 \\
\hline E11 & & & & & .516 \\
\hline E12 & & & & & .526 \\
\hline E13 & & & & & .595 \\
\hline
\end{tabular}

Note. Rotation method: Varimax with Kaiser Normalization.

Source: Author's estimation.

Thus, the purpose of factor analysis is to check the correlation between the items of each variable and make grouping of the items on the basis of correlation between them. There are two types of factor analysis - namely exploratory factor analysis (EFA) and confirmatory factor analysis (CFA). The research however used EFA technique, which is used to identify the initial correlation among the items. There were total 38 items in the initial factor loading for the five variables. However, during the process of exploratory factor analysis, the research needed to exclude seven items which possibly did not fit in the current context of research. Thus, finally 31 items were successfully loaded in the principal components analysis result. The details of the final factor loading are given in the table above.

The seven deleted items were most possibly taken out of context by the respondents and hence could not correlate into the other items of their respective variables. For example, the item "I do not worry in understanding the more complex aspects of English" must have been responded in "disagree" column as per the grading scale of Gardner (1985), but the students took it as positive and hence most of the students attempted the "agree" column. Similarly, the item "studying English is important because other people will respect me more if I know English" was again taken into its negative aspect. Students believed to be a good point in learning English but did not agree with the notion that knowing English is the only benchmark of respect in a homogenous society. Another similar item was about appreciating the English way of life, that is, "studying English is important because it will enable me to better understand and appreciate the English way of life". Here again, as per researcher's own anticipation, the students might not be willing to 'appreciate' the English way of 
life hence the responses from students did not correlate the other responses of the same variable. Some of the students also responded negatively towards the question "I prefer to spend my time on subjects other than English". Technically, the students were supposed to disagree with this statement but most of the students made healthy agreed responses possibly due to the fact that they thought of giving equal time towards all the subjects they study while the medical and pre-engineering students tend to give extra time to subjects other than English, that is, the science subjects, as part of their course requirements. Besides all these anomalies, mostly the students showed a positive attitude and motivation towards learning English as a foreign language because it was the language which they need the most in their future careers, hence learning English was inevitable and the need of the hour.

In addition to the above, there were 15 items coded negatively among the 38 initial items, five each in the initial variables namely: motivation intensity, desire to learn English, and attitude towards learning English. The researcher decoded students' responses from negative column "disagree" to positive column "agree", as per the rules of SPSS data insertion. Somehow, during exploratory factor analysis, the principal components matrix grouped 13 negatively encoded items into one variable while two items were eliminated as it did not correlate with any of the variable items. Hence the variable names and items were rearranged by the scholar into five variables namely: motivation intensity (five items), desire to learn English (two items), attitude towards learning English (five items), instrumental and integrative motivation (six items), and motivational orientation (13 items). After loading of the final items, the confirmatory factor analysis (CFA) was performed to check the final correlation among the items of the individual variables which was found identical to the one produced in EFA (referred to previous table). After running CFA, the 31 remaining items were ready to be run through SPSS for t-test.

\subsection{Independent-sample t-test}

The statistical procedure known as t-test is used to measure the mean of two or more variables to for the purpose of comparison between two or more entities. There are three types of t-tests available for different purposes including one-sample $t$-test, independent-sample $t$-test, and paired-sample $t$-test depending upon the number of variables to be compared. As in current research, there are two entities to be compared, that is, public and private students in the variable named mode of education. The comparison is made taking different constructs into consideration, that is, motivation, attitude, and desire to learn and many others. The procedure for independent-sample t-test initiates with the assumed hypothesis that the mean values of both the entities under comparison are equal, that is, the null hypothesis $\mathrm{H}_{0}=$ Both means are equal. After the comparison through SPSS the obtained sig value is checked and if the value of sig $>0.1$ then the claim is accepted that both means are equal, that is, the mean values are not different. Conversely, if the sig $<0.1$ then null hypothesis is rejected and it is assumed that a significant difference exists between the mean values of two comparative entities. The t-test for equality of mean against each variable is discussed below in detail.

Variable one (Motivation Intensity) - An independent sample t-test was conducted to compare the motivation intensity of public and private school students. The mean and standard deviation values for motivation intensity are represented as under. The mean value of public school students was 4.99 while that of private school students was 5.21, thus having a value of -0.22 as the mean difference. Similarly, the mean value for male students was 5.05 and that for female students was 5.15 , so, the mean difference in this case was -0.10 . In the variable motivation intensity, the significant difference was not found in the scores of public school students $(\mathrm{M}=4.99, \mathrm{SD}=0.82)$ and private school students $(\mathrm{M}=5.22, \mathrm{SD}=0.49)$ with conditions $\mathrm{t}(398)=3.19$, $p=.002$. However, a significant difference was found on the basis of gender motivation intensity in the values of male students $(\mathrm{M}=5.05, \mathrm{SD}=.72)$ and female students $(\mathrm{M}=5.15, \mathrm{SD}=.62)$ in statistical conditions $\mathrm{t}(398)=1.48$, $p=.141$ which indicated that female students had more motivational intensity for learning English as compared to male students.

Variable two (Desire to Learn English) - Similarly, the t-test for the variable desire to learn English (DLE) 
was administered in similar fashion and found public students' mean value as 4.93 while private students' as 5.23 with a mean difference of -0.31 . Additionally, the mean value of male students was reported as 5.06 and that for female students was 5.11 with a mean difference as -0.05 which is considered as insignificant difference. In the variable desire to learn English, no significant difference was observed in the values of public school students $(\mathrm{M}=4.93, \mathrm{SD}=1.17)$ and private school students $(\mathrm{M}=5.23, \mathrm{SD}=0.69)$ with conditions $\mathrm{t}(398)=3.19, p=.001$. On the other hand, a significant difference was available on the basis of gender in the scores of male students $(\mathrm{M}=5.06$, $\mathrm{SD}=.99)$ and female students $(\mathrm{M}=5.11, \mathrm{SD}=.95)$ with conditions $\mathrm{t}(398)=.54, p=.590$ indicating that female students were more desirous to learn English than the male students.

Variable three (Attitude towards Learning English) - Furthermore, the values obtained through t-test for public students as 5.27 and private students as 5.49 in the variable ALE. Here the mean difference was -0.22 and again as par with the previous two variables, the attitude of private students towards learning English was more positive as compared to the public institute students. In a similar comparison, the mean value of male students was 5.28 and that of female students was 5.51 with a significant mean difference value of -.23 indicating that the attitude of female students towards learning English was more positive as compared to male students. In the variable attitude towards learning English, no significant difference was found in the values of public school students $(\mathrm{M}=5.27, \mathrm{SD}=.84)$ and private school students $(\mathrm{M}=5.49, \mathrm{SD}=.55)$; conditions $\mathrm{t}(398)=3.17, p=.002$, as well as in the scores of male students $(\mathrm{M}=5.28, \mathrm{SD}=.82)$ and female students $(\mathrm{M}=5.51, \mathrm{SD}=.53)$; conditions $\mathrm{t}(398)=3.25, p=.001$.

Variable four (Instrumental \& Integrative Motivation) - Instrumental and integrative motivation (IIM) was the fourth variable of the scale. The same pattern of behavior was observed for this variable as was with the previous three constructs. The mean value for public institute students was found as 5.31 while that for private institute students was obtained as 5.56. Hence, the mean difference for the two entities was -0.25 . Here, again, the - sign shows that the instrumental and integrative motivation of public school students was less than those of private schools. In addition, the mean value for male students was 5.35 and female students was 5.56 and the reported mean difference was -.21 which describes the higher instrumental and integrative motivation of the female students. Again, for this variable, no significant difference was established in the values of public school students $(\mathrm{M}=5.31, \mathrm{SD}=.83)$ and private school students $(\mathrm{M}=5.56, \mathrm{SD}=.49)$; conditions $\mathrm{t}(398)=3.69, p=.000$, as well as in the scores of male students $(\mathrm{M}=5.35, \mathrm{SD}=.75)$ and female students $(\mathrm{M}=5.56, \mathrm{SD}=.58)$; conditions $\mathrm{t}(398)=2.99, p=.003$.

Variable five (Motivational Orientation) - Finally, motivational orientation was the last variable which was analyzed using independent-sample t-test. The results for this test were also similar and identical to the above four constructs with a huge difference of mean reported for this final variable. The mean value of public school students was 4.58 while it was 5.34 for the private school students. Consequently, the difference of mean was considerably large, that is, -0.76 and indicated a huge difference of motivational orientation towards English present between public and private high and higher secondary school students. Again, public school students were less motivated as compared to the private school students. Furthermore, the comparison was also made on the basis of students' gender which indicated that female students were having a higher level of motivational orientation towards learning English as compared to their male counter parts with the mean vale of 4.80 for male students and 5.16 for male students and having a significant mean difference value of -0.36 . The said values are given in the previous tables. Once again, for motivational orientation construct, a significant mean difference was not found in the scores of public school students $(\mathrm{M}=4.58, \mathrm{SD}=.99)$ and private school students $(\mathrm{M}=5.34$, $\mathrm{SD}=.45)$; in the conditions $\mathrm{t}(398)=9.82, p=.000$, and that of male students $(\mathrm{M}=4.80, \mathrm{SD}=.92)$ and female students $(\mathrm{M}=5.16, \mathrm{SD}=.73)$; with conditions $\mathrm{t}(398)=4.22$, and $p=.000$ value.

\section{Conclusion and Recommendations}

The data analysis part of the current research has pointed out a significant level of motivation for and attitude towards learning English as foreign language among public and private high and higher secondary 
school students in Pakistan. The mean values of each variables was above 4.5 in either case, that is, both for public and private male and female students compared with 6 as the peak value for each item. In this regard, 375 (94\%) students agreed to the question that they really work hard to learn English. This indicates that students in Pakistan are highly motivated towards learning English. Furthermore, a total of 384 (96\%) gave a positive response to the question that learning English is really great and 374 (94\%) students responded that they really enjoy while learning English. Thus, mostly the attitude of the students was positive towards learning English, which can be considered as a milestone in internalization of English as a medium of instruction as well a source of communication in literary and non-literary circles of Pakistani society. In addition to that, as many as 388 (97\%) students agreed with the growing fact that they will need English to proceed for their careers in future. In this way, learning English is considered as an instrumental motivation factor for the students in Pakistan.

Although most of the respondents were motivated towards learning English, yet the results of t-test statistics proved that the students from private sector schools and colleges were more motivated and showed a more positive attitude towards learning and using English for their pedagogical as well as social and economic needs as compared to their peers at public sector schools and colleges. Most significant difference was reported in the motivational orientation construct where the mean difference in the motivation level of the students was calculated as approximately 0.76 in the favor of students studying under private mode of education. The probable reason behind this notion might be the high standard of education along with most appropriate facilities provided to private school students as compared to the public level students. Consequently, these facilities and higher literary resources motivate the students through building a positive attitude towards learning English as a foreign language which has the potential to grant them a secure future in its financial and social perspective. On the other hand, although the public school students are also mostly motivated towards learning English but perhaps the lesser resources and less instructor support cause them to lag behind the private school students when the motivation and attitude towards English is compared. There might be few students who just have no pedagogical plan for future and thus get admission in public colleges just for fun and time-pass. These students too can be a reason that private students lead the public school students in motivation and attitude attire.

Proceeding further into the comparison through independent sample t-test, the researcher made a similar comparison of students' motivation and attitude towards learning English on the basis of their gender. A significant level of difference of motivation level and attitude found among male and female students. Female students were having more positive attitude and high motivation level for learning English as foreign language as compared to the male students in all five constructs measured by the researcher. The most significant difference was reported in the variable motivational orientation where the mean difference between male and female students stood 0.36 in the favor of female students, thus proving that female students were more inclined towards English language. Similarly, other four variables also demonstrated a similar pattern of mean difference in the favor of female students.

The researcher, after a careful analysis and interpretation of students' results, proposes that the concern authorities must provide basic facilities in public schools as well as colleges in par with the private schools so that these facilities may serve integrative motivation for the public institute students to turn their attitude towards English more positive. There must be a student counseling department available in every public sector college. The function of that department should be to provide the counseling about their careers and the importance of English must be highlighted through these student counselors. The teachers should also employee best teaching practices along with the use of effective language learning strategies. There were 36 public sector students who agreed that they will leave the study of English after passing out from the college because they were not interested in it. The use of effective teaching practices along with the use of most suitable language learning strategies can make learning English language interesting for the less motivated students. The use of technology and computer assisted language learning particularly in the government sector can also prove helpful in raising the motivation level of the students. Thus the level of motivation and attitude of the public sector students can be enhanced to make it at par with the private sector students through the implementation of above stated recommendations. 
The study has implications for different stakeholders like parents, teachers, and school management. The teachers can take lead from this study to enhance the motivation level for their students as well as to garner a positive attitude among them to enhance their learning outcomes. Similarly, parents too can further motivate their children in order to polish their receptive learning abilities. School management has much to gain from the study as it will enhance the learning capabilities of the students of their institution. There were certain limitations associated with the present study in terms of time constraints. The study was conducted only taking 400 samples from only districts of Pakistan. Moreover only one research technique (quantitative methods) was used. However, future researchers can take lead from this study and add more features to improve the content of the study. The current study can be explored further into the motivation and attitude factors among Pakistani students. An addition of qualitative portion of the study can further enhance the usefulness of the current research.

Acknowledgement - The researcher acknowledges the important contributions made by different figures throughout this research. A special thanks for the worthy supervisor whose encouragement and continuous help made this project viable and successful. Researcher pays handful of gratitude to the institutional management who allowed the research for this study and the students who actively and passionately participated in the actual study. And finally the research department of Iqra University helped the research in the course of data analysis through SPSS.

\section{References}

Acharya, A. S., Prakash, A., Saxena, P., \& Nigam, A. (2013). Sampling: Why and how of it? Indian Journal of Medical Specialties, 4(2), 330-333. https://doi.org/10.7713/ijms.2013.0032

Akram, M. (2015). Arab students' motivation in learning English: A study of PYP students. European Centre for Research Training and Development UK, 3(2), 80-90.

Ali, M. S., \& Pathan, Z. H. (2017). Exploring Factors causing demotivation and motivation in learning English language among college students of Quetta, Pakistan. International Journal of English Linguistics, 7(2), 81-89. https://doi.org/10.5539/ijel.v7n2p81

Al-Mahrooqi, R., Hassan, S., \& Cofie, C. (2016). Analyzing the use of motivational strategies by EFL teachers in Oman. Malaysian Journal of ELT Research, 8(1), 36-76.

Barnett, T., Pearson, A. W., Pearson, R., \& Kellermanns, F. W. (2015). Five-factor model personality traits as predictors of perceived and actual usage of technology. European Journal of Information Systems, 24(4), 374-390. https://doi.org/10.1057/ejis.2014.10

Bekiari, A., \& Petanidis, D. (2016). Exploring teachers' verbal aggressiveness through interpersonal attraction and students' intrinsic motivation. Open Journal of Social Sciences, 4(12), 72-85. https://doi.org/10.4236/jss.2016.412007

Boo, Z., Dörnyei, Z., \& Ryan, S. (2015). L2 motivation research 2005-2014: Understanding a publication surge and a changing landscape. System, 55, 145-157. https://doi.org/10.1016/j.system.2015.10.006

Busse, V. (2017). Plurilingualism in Europe: Exploring attitudes toward English and other European languages among adolescents in Bulgaria, Germany, the Netherlands, and Spain. The Modern Language Journal, 101(3), 566-582. https://doi.org/10.1111/modl.12415

Cheng, H. F., \& Dörnyei, Z. (2007). The Use of motivational strategies in language instruction: The case of EFL teaching in Taiwan. Innovation in Language Learning and Teaching, 1(1), 153-174. https://doi.org/10.2167/illt048.0

Dornyei, Z. (2001). New themes and approaches in second language motivation research. Annual review of applied linguistics, 21, 43-59. https://doi.org/10.1017/S0267190501000034

Dornyei, Z., \& Otto, I. (1998). Motivation in action: A process model of L2 motivation. Working Papers in Applied Linguistics, 4, 43-69.

Eagly, A. H., \& Chaiken, S. (2007). The advantages of an inclusive definition of attitude. Social cognition, 25(5), 582-602. https://doi.org/10.1521/soco.2007.25.5.582 
Attitude and motivation towards English as foreign language to secondary school students in Pakistan

Garder, R. C. (2010). Motivation and second language acquisition: The socio-educational model. New York, NY: Peter Lang.

Gardner, R. C. (2006). The socio-educational model of second language acquisition: A research paradigm. EUROSLA Yearbook, 6(1), 237-260. https://doi.org/10.1075/eurosla.6.14gar

Gardner, R. C. (2007). Motivation and second language acquisition. Porta Linguarum, 8, 9-20.

Gardner, R.C. (1985). Social psychology and second language learning: The role of attitude and motivation. London: Edward Arnold.

Grey, S., Williams, J. N., \& Rebuschat, P. (2015). Individual differences in incidental language learning: Phonological working memory, learning styles, and personality. Learning and Individual Differences, 38, 44-53. https://doi.org/10.1016/j.lindif.2015.01.019

Khalid, A. (2016). A study of the attitudes and motivational orientations of Pakistani learners toward the learning of English as a second language. SAGE Open, 1-16. https://doi.org/10.1177/2158244016665887

Kolb, A. Y., \& Kolb, D. A. (2005). Learning styles and learning spaces: Enhancing experiential learning in higher education. Academy of management learning \& education, 4(2), 193-212. https://doi.org/10.5465/amle.2005.17268566

Kormos, J., Kiddle, T., \& Csizér, K. (2011). Systems of goals, attitudes, and self-related beliefs in second-language-learning motivation. Applied Linguistics, 32(5), 495-516. https://doi.org/10.1093/applin/amr019

Liu, Y., \& Lin, A. M. (2017). Popular culture and teaching English to speakers of other language. In Language, Education and Technology (pp. 87-101). Springer. https://doi.org/10.1007/978-3-319-02237-6_38

Mahboob, A. (2017). English medium instruction in higher education in Pakistan: Policies, perceptions, problems, and possibilities. In Walkinsah, I., Fenton-Smith, B., \& Humphreys, P. (Eds.), English as a medium of instruction in higher education in Asia-Pacific: Issues and challenges (pp. 71-92). London: Springer. https://doi.org/10.1007/978-3-319-51976-0_5

Manzoor, F., Ahmed, M., \& Gill, B. R. (2014). Use of motivational expressions as positive reinforcement in learning English at primary level in rural areas of Pakistan. British Journal of English Linguistics, 2(3), $30-42$.

Nawaz, H., Amin, M., \& Tatla, I. A. (2015). Factors affecting students' motivation level to learn English as a second language in the Pakistani university context. Journal of Research and Reflections in Education, 9(2), 103-115.

Noreen, S., Ahmed, M., \& Esmail, A. (2015). Role of students' motivation, attitude and anxiety in learning English at intermediate level in Pakistan: A gender based study. Educational Research International, 4(2), 96-108.

Raza, S. A., Jawaid, S. T., \& Hassan, A. (2015). Internet banking and customer satisfaction in Pakistan. Qualitative Research in Financial Markets, 7(1), 24-36.

Rehman, A., \& Haider, K. (2013). The impact of motivation on learning of secondary school students in Karachi: an analytical study. Educational Research International, 2(2), 139-147.

Shakfa, M. D., \& Kabilan, M. K. (2017). The role of motivation in enhancing the Palestinian students' English language learning. INSANCITA, 2(1), 1-16. 
Bajwa, I., \& Younas, M. 